Article

\title{
Investigation of Heat Treatment Strategies for Additively-Manufactured Tools of X37CrMoV5-1
}

\author{
Daniel Junker ${ }^{1, *}$, Oliver Hentschel ${ }^{2}$, Michael Schmidt ${ }^{2}$ and Marion Merklein ${ }^{1}$ \\ 1 Institute of Manufacturing Technology, Friedrich-Alexander-Universität Erlangen-Nürnberg, Egerlandstr. 13, \\ 91058 Erlangen, Germany; marion.merklein@fau.de \\ 2 Institute of Photonic Technologies, Friedrich-Alexander-Universität Erlangen-Nürnberg, Konrad-Zuse-Str. 3, \\ 91052 Erlangen, Germany; oliver.hentschel@lpt.uni-erlangen.de (O.H.); \\ michael.schmidt@lpt.uni-erlangen.de (M.S.) \\ * Correspondence: daniel.junker@fau.de; Tel.: +49-9131-85-20768
}

Received: 8 October 2018; Accepted: 16 October 2018; Published: 19 October 2018

check for updates

\begin{abstract}
For cost-intensive products like automobiles, clients often wish to personalize their product, what forces the industry to create a large diversity of combinable parts. Additionally, the life cycles of many components become shorter. For highly-stressable parts, which are commonly manufactured by forging, the short changeover cycles result in expensive products, as the costs of tools must be offset by the sale of only a few parts. To reduce the tool cost, new, flexible processes have to be established in tool manufacturing. Laser-based additive manufacturing is noted for its high flexibility; notably, Laser Metal Deposition (LMD) is gaining increasing relevance in research, as it is already used for coating and repairing forming tools, this technology makes it possible to add material onto free-formed surfaces. Therefore, investigations are being conducted to qualify this process to produce forging tools. Due to the thermal processes which are required during additive manufacturing, the microstructure of the material differs from that of wrought material. This, in turn, affects the strategy of post heat treatment in order that the required mechanical properties for tools be attained. Within this manuscript, the influence of additive manufacturing on performance characteristics of hot work tool steel X37CrMoV5-1 (1.2343) is analyzed. To investigate the behavior of additively manufactured material during the process chain of tool manufacturing, properties for different states of a heat treatment are characterized by hardness and strength. It was shown that the strength of the additively manufactured material could be increased compared to wrought material by using a tailored heat treatment. The effects that cause this behavior are investigated by comparing the microstructure at different states of heat treatment.
\end{abstract}

Keywords: directed energy deposition; heat treatment; microstructure

\section{Introduction}

Additive manufacturing is gaining more and more importance in industrial applications, as the stability and accuracy of the processes in this field have increased substantially over the last few years. This manufacturing technology offers great potential regarding high flexibility and geometrical freedom. This technology enables an easier consideration of costumers' requirements to produce individualized products. The parts are manufactured directly from Computer-Aided Design (CAD) without a specific tool and with almost no geometrical limitations, depending on the additive manufacturing process that is used [1]. The main challenges of this technology are rough surfaces and the reliable reproducibility of mechanical properties. Especially for highly-loaded parts, these limitations could lead to premature failure of the component. To use high flexibility, even for those highly-loaded parts, the implication of additive manufacturing for tool manufacturing for bulk 
metal forming has to be investigated. The most promising processes within this context are laser-based Powder Bed Fusion (PBF) [2] of metal material, also known as Laser Beam Melting (LBM) [3], and laser-based Directed Energy Deposition (DED) [2], also known as Laser Metal Deposition (LMD) [4]. These processes make it possible to produce metallic structures with a relative density of more than 99.5\%. The most commonly-used material for tools produced by LBM is X3NiCoMoTi18-9-5 (DIN 1.2709/AISI MS1). Although the application for forging tools was successfully tested by Huskic et al. [5], this tool steel is not established in tool production due to the limited high-temperature strength and inclusions of titanium oxide in parts built by LBM [6]. To process more commonly-used high carbon tool steels like X37CrMoV5-1 (DIN 1.2343/AISI H11) by LBM, a modification of the machine setup is necessary, due to structural transformations of high carbon steel during the thermal processes caused by the laser. To reduce thermally-induced residual stresses, martensitic transformation has to be prevented by heating the baseplate above the martensitic start temperature.

In contrast, LMD is already established for coating and repair applications of cost-intensive goods like tools [7]. The open machine setup gives us the opportunity to easily make modifications e.g., the integration of a substrate heater that is needed in most welding processes using high carbon tool steel. However, the three-dimensional additive manufacturing of complete active tool elements is still under scientific investigation. Within this process, shown in Figure 1, a laser beam is directed through a working head and focused onto a workpiece that generates a melt pool. For additive manufacturing, the powder material is injected into the melt pool by a powder nozzle. After cooling and solidification, a welded track is added onto the substrate surface. To protect the melt pool from oxidation, inert gasses like argon or helium are used as Shield gas and transport gas. For additive manufacturing of three-dimensional parts, single tracks are welded side-by-side to the various layers, and several layers onto each other. Modern technology and software even enables the deposition on free-formed surfaces. Nowadays, the material spectrum that is used for LMD is limited to stainless steel [8], low carbon tool steel [9], nickel base alloys, and pure metals like nickel [10] or titanium [4], as well as the embedding of not fusible particles in one of the named materials [11].

For applications in tool coating or reparation, good weldable materials like stellite 21 [12] are used instead of conventional, high carbon tool steels. These substitute materials are not suitable for the manufacturing of whole active forming elements for forming tools. Therefore, the processing of high-carbon tool steels like X40CrMoV5-1 [13] or 60CrMoV18-5 [14] is currently under scientific investigation. Within these investigations, the effects on the microstructure and on hardness were proven for different parameters and the thermal conditions during and after manufacturing [13]. This investigation was limited to a coating of hot work tool steel X40CrMoV5-1.

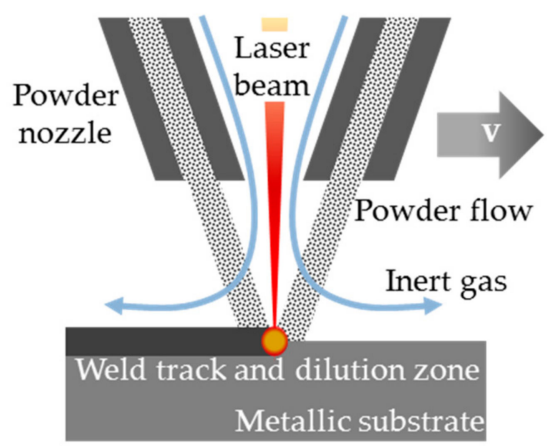

Figure 1. Schematic principle of Laser Metal Deposition (LMD). Adapted from [14].

For three-dimensional, additively-manufactured structures, this effect could be more significant, as the microstructure of each layer is influenced by the thermal conditions during the manufacturing process, as well as by the thermal conditions caused by thermal conduction while adding additional layers on top. Furthermore, the microstructure not only influences the material's hardness, but also significantly affects the mechanical properties like tensile and compression strength, as well as ductility. 
Moreover, additively-manufactured parts are commonly heat treated before usage to reduce residual stresses and to homogenize the structure. In addition to this, for tool steels, heat treatment is necessary to obtain the required mechanical properties for bulk metal forming tools. Within this context, the microstructure before heat treatment has a huge effect on the resulting material properties.

To analyze the effect of the LMD process on the resulting material properties, a characterization for additively-manufactured parts of hot work tool steel X37CrMoV5-1 is conducted. The mechanical properties like hardness and material behavior during compression or tensile tests are analyzed after conducting different heat treatment strategies. To interpret the results, a comparison to conventionally-manufactured specimens is made, and the microstructure is analyzed and connected to the results of the characterization.

\section{Experimental Setup}

To manufacture the specimens for the planned investigations, first, the parameter window to process the hot work tool steel was developed. Afterwards, the specimens for the mechanical characterization were manufactured with suitable parameters, as shown in Figure 2.

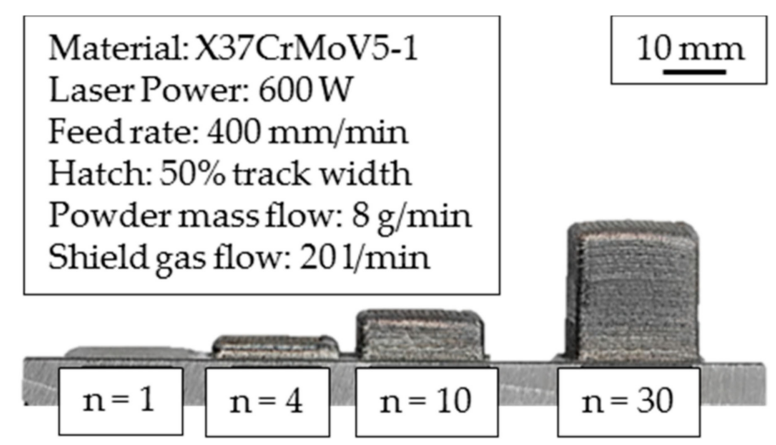

Figure 2. Evolution of three-dimensional cuboids using Laser Metal Deposition (LMD) according to [14]. To receive high geometrical accuracy, the $z$-shift must be adjusted every few layers.

\subsection{Laser Metal Deposition (LMD)}

The experiments for processing the hot work tool steel X37CrMoV5-1 by LMD were conducted on a Laser Metal Deposition machine TLC 3008, produced by Trumpf GmbH \& Co. KG (Ditzingen, Germany). The machine is equipped with a disk laser of a maximum average $\mathrm{cw}$-laser power of $1 \mathrm{~kW}$, a 5 -axis motion system, a gravimetric powder feeder unit with two powder hoppers, and a laser processing head combined with a zoom-optic and three-way powder nozzle. To analyze the parameters for processing the hot work tool steel, the methodology according to [14] is applied.

After a particle analysis, the suitable parameters were narrowed down by producing and investigating single weld tracks on substrates of the same tool steel. Afterwards, the parameter window was isolated by welding a whole layer and further multiple layers onto each other, as illustrated in Figure 2. Using this methodology, the ideal parameters for a stable process that produces parts of a relative density of $99.9 \%$ can be achieved. Due to the function principle of LMD, the structures are built directly onto the substrate without any support structure. After analyzing the porosity of additively-manufactured cuboids of the high carbon hot work tool steel X37CrMoV5-1, a narrow process window was identified. In order to guarantee robust processing, the following parameters are chosen for the experiments to manufacture the specimens for the material characterization (shown in Figure 2): laser power of $600 \mathrm{~W}$, a feed rate of $400 \mathrm{~mm} / \mathrm{min}$, a hatch distance of $50 \%$ of the track width, a powder mass flow of $8 \mathrm{~g} / \mathrm{min}$, and a shield gas flow of $20 \mathrm{~L} / \mathrm{min}$.

\subsection{Heat Treatment Variation for Additively-Manufactured X37CrMoV5-1}

The focus of the presented work is an analysis of the influence of the successive build up and the thermal processes during LMD on the microstructure and the mechanical properties of 
additively-manufactured tool steel. Notably, the microstructure has an effect on a post heat treatment strategy and the resulting mechanical properties. For the investigation, the specimens for the material characterization were heat treated. To analyze the influence of the thermal processes during additive manufacturing, different heat treatment strategies, as shown in Table 1, were conducted. As a reference, the material properties after additive manufacturing are analyzed. In general, tool steel is tempered after hardening to reduce residual stress and to increase the ductility of the material. Due to the high cooling rate during the LMD process, the resulting structure is expected to be similar to conventionally-manufactured materials after hardening. Therefore, a heat treatment of three times tempering without preaustenitization is compared to a conventional heat treatment of the additively manufactured specimens with austenitization and three times tempering.

The heat treatment, illustrated by the temperature-time cycles in Figure 3, was realized with an austenitization at $1080^{\circ} \mathrm{C}$ and three times tempering at a temperature of $570{ }^{\circ} \mathrm{C}$ for about two hours. To guarantee the comparability, all specimens were tempered simultaneously.

Table 1. Experimental plan for the investigations of additive manufactured specimens.

\begin{tabular}{lcc}
\hline No. & Condition & Post Process/Explanation \\
\hline 1 & As built & No heat treatment after additive manufacturing \\
2 & Hardened & Hardening by austenitization and quenching \\
3 & Heat treated & Conventional heat treatment with austenitization, qunching and three times tempering \\
4 & Tempered & Three times tempering without preaustenitization \\
\hline
\end{tabular}
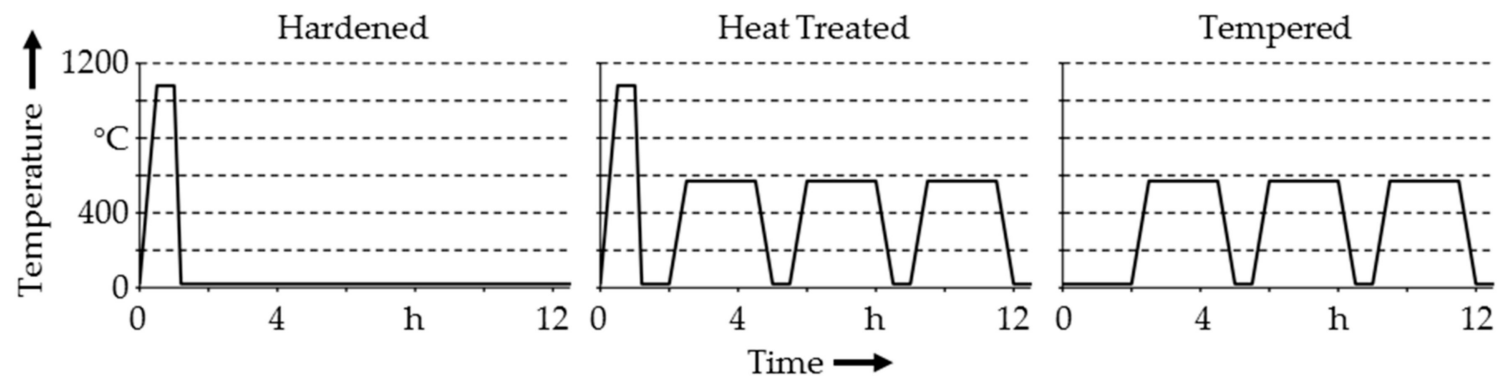

Figure 3. Temperature-Time cycles of the conducted heat treatments.

\subsection{Material Characterization of Additively-Manufactured X37CrMoV5-1}

To qualify the additive manufactured specimens, the material properties like hardness and yield strength are analyzed. The hardness measurements are conducted on a Fischerscope HM2000 from the Helmut-Fischer GmbH (Sindelfingen, Germany), which gives the opportunity of a high-resolution measurement of the Vickers Hardness (HV0.5). For the measurement, cross sections of cuboids with an edge length of $15 \mathrm{~mm}$ are plane parallel grinded and polished. As the additive manufacturing has main influence on the hardness in z-direction [9], the point distance is set on $0.2 \mathrm{~mm}$ for a high resolution. In the horizontal direction, 6 lines with a point distance of $1 \mathrm{~mm}$ are set. For forming tools, a high hardness is required to reduce wear. The high hardness correlates with the strength of tool materials that is needed to prevent a plastic deformation of a tool. Fractures mainly occur due to tensile stresses, as tool steel in general has a brittle fracture behavior and cannot resist high strain.

Therefore, the mechanical properties are analyzed by compression as well as tensile tests. The cylindrical specimens, shown in Figure 4, with a diameter of $\varnothing 6 \mathrm{~mm}$ and a height of $9 \mathrm{~mm}$ for the compression tests, are machined from additively built cuboids with an edge length of $15 \mathrm{~mm}$. The tests are conducted on a universal testing machine FS300 from Walter + Bai AG (Löhningen, Switzerland) with a maximum force of $300 \mathrm{kN}$. Due to the high load during compression testing, carbide tools are used as the upper and lower dies. A layer of teflon foil between the specimen and tool guaranties constantly low friction. According to DIN 50106 [15], the tests are executed with a compression velocity of $5 \mathrm{~mm} / \mathrm{min}$. After a compression of 35\% of the initial height of the specimen, the tests are aborted. 
The tensile tests are conducted according to DIN EN ISO 6892-1 [16]. The specimen's geometry, shown in Figure 4, is based on form B of DIN 50125 [17], with a measuring diameter of $\varnothing 6 \mathrm{~mm}$ and a measuring length of $30 \mathrm{~mm}$. As tool steel in general has a brittle fracture behavior, a thread of M12 is designed instead of M10 to minimize a notch effect within the thread section of the specimen. To produce the samples for the tensile tests, three blocs with an edge length of $80 \mathrm{~mm}$ and a height of $15 \mathrm{~mm}$ were built using a LMD. This procedure was chosen to guarantee a homogeneous additively-manufactured structure, and to reduce the influences of structural transformations near the surface. Due to thermal processes during additive manufacturing using LMD, the last few layers have a different microstructure, as they are not tempered by the production of further layers [9]. After heat treatment, these blocs were separated into five sticks by wire cutting, and afterwards, the specimen's geometry according to form B of DIN 50125 was turned out of these sticks and subsequently polished to a surface roughness of $\mathrm{Ra} 0.5 \mu \mathrm{m}$. The polishing is conducted in order to reduce the effect of work hardening caused by the chipping production, and to reduce notch effects of the rough surface after additive manufacturing. The tests are executed with the same universal testing machine. Until the yield strength YS is reached, the test speed is stress controlled with a rise of $20 \mathrm{MPa} / \mathrm{s}$. Afterwards, the speed is strain-controlled at $0.008 / \mathrm{s}$.

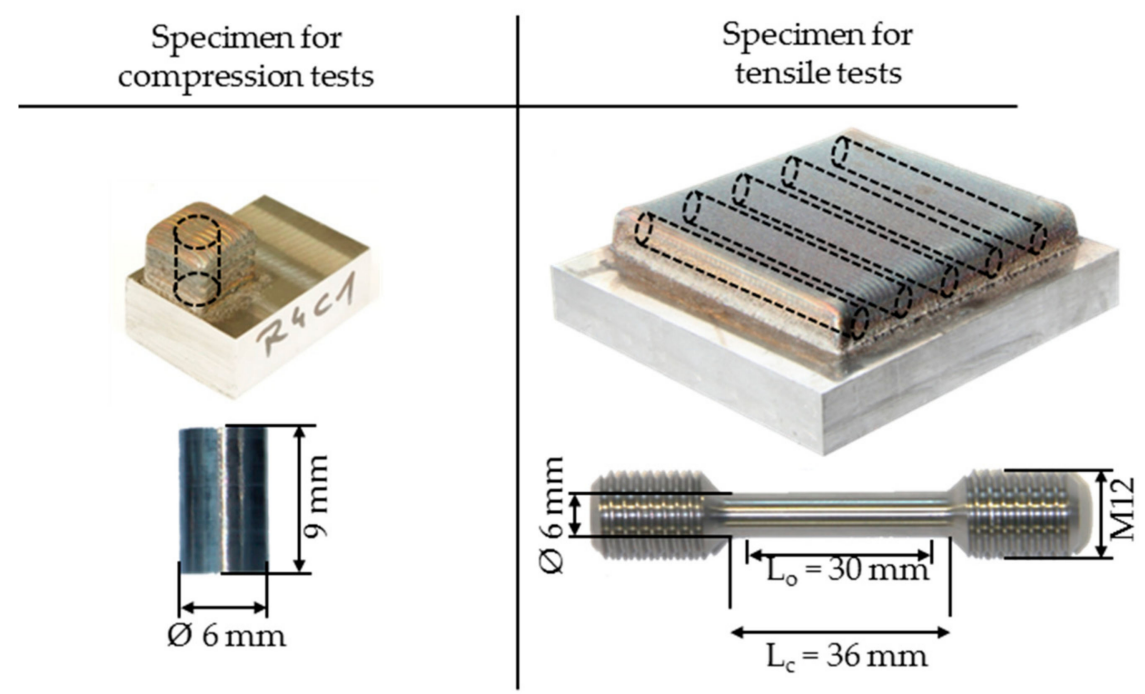

Figure 4. Production and geometry of the specimens for the tests of mechanical properties. To eliminate boundary effects, the specimens are machined out of relatively large structures.

\subsection{Metallographic Analysis}

The investigation of the microstructure was conducted on the polished cross sections also used for the hardness measurement. To identify the structural characteristics, the samples are etched with V2A mordant for $15 \mathrm{~s}$ and analyzed by optical microscopes. An investigation of the element distribution was made using an energy dispersive X-ray (EDX) of the Scanning Electron Microscope (SEM) Merlin Gemini 2 VP Compact 6143 from Carl Zeiss AG (Oberkochen, Germany). This allows us to undertake local analysis of the distribution of alloying elements. Additionally, an analysis of the portion of retained austenite was conducted using the X-ray diffractometer Stress Analyser XRD 3003 from Rich. Seifert \& Co (Ahrensburg, Germany). By analyzing the reflection of a directed X-ray beam for different measuring angles, the structure of the atomic grid can be identified, what enables a prediction of different materials phases.

\section{Results}

First, the mechanical properties of the additively-manufactured structures are investigated. For the interpretation of the results, the microstructure is analyzed. The aim of this work is the identification 
of a correlation of the mechanical properties and the microstructure. To minimize statistical effects, 5 samples were tested for each analyzed variation. Within this section, at first the results of the different experiments are shown. Afterwards, a correlation between the mechanical and structural material properties will be discussed.

\subsection{Hardness Measurement}

Hardness is an important property for tool steels regarding wear resistance, therefore, it is measured with a fine grid in $z$-direction, as described above. The results of the mean values in $z$-direction are shown in Figure 5. From left to right, the hardness transition from the substrate to the additively-manufactured part can be seen. The hardness of the non-heat-treated specimens rises from the soft annealed substrate with about 300 HV0.5 through the heat affected zone of the first layer to the additively-manufactured structure of about 730 HV0.5.

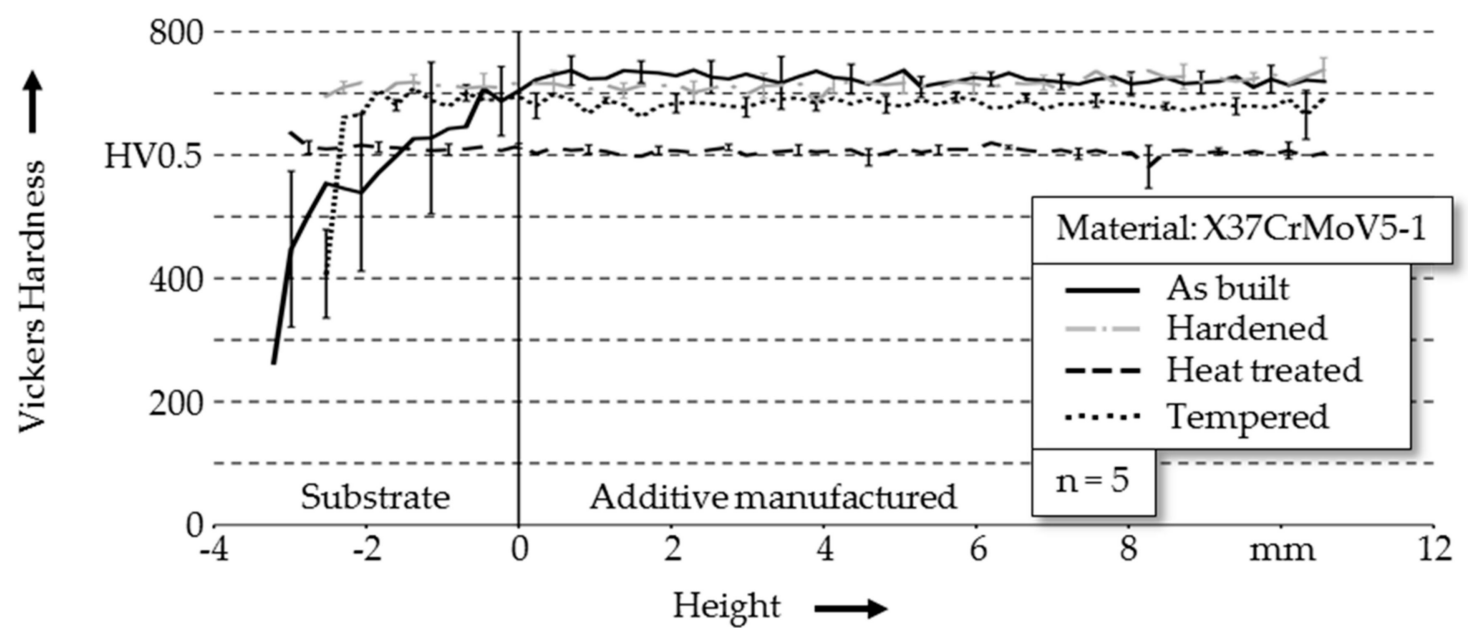

Figure 5. Hardness in $z$-direction.

The hardness of 730 HV0.5 is similar to the hardness measured after hardening, in which no difference between the conventionally-manufactured substrate and the additively-manufactured element can be identified. Therefore, the heat treatment of three times tempering without austenitization is analyzed to investigate the substitution of this cost-intensive process step within tool production when using LMD. After tempering, the substrate is still soft annealed, but the hardness is slightly lowered to a mean value of about 690 HV0.5. After conventional heat treatment, the substrate and the additively-manufactured cuboid have a mean hardness of about 600 HV0.5. As the substrate represents a conventionally-manufactured tool steel X37CrMoV5-1, it is proven that, after conventional heat treatment, the hardness of the additively-manufactured part is similar to that of the conventionally-manufactured part.

\subsection{Compression Test}

Bulk-metal-forming tools are mainly loaded by compression stress. To prevent plastic deformation, high compression yield strength is required for tool materials. To qualify the additively-manufactured elements, compression tests are conducted for the different heat treatments. To evaluate the results, tests with conventional material are executed directly after hardening, and after conventional heat treatment. Regarding the results shown in Figure 6, the positive effect of an adapted heat treatment can be identified. This condition cannot be produced with conventional materials, as the initial state for this heat treatment is the microstructure resulting from additive manufacturing.

Without any heat treatment after additive manufacturing, the compression yield strength, shown in Figure $6 \mathrm{a}$, is at about $1770 \mathrm{MPa}( \pm 13 \mathrm{MPa})$, which is near the compression yield strength of conventionally-manufactured material after hardening, i.e., about $1810 \mathrm{MPa}( \pm 8 \mathrm{MPa})$. These results 
support the hypothesis of an in-situ hardening during additive manufacturing due to the fast cooling from a molten state. Within high carbon tool steel, the fast cooling leads to a freezing of the austenitic microstructure, which results in a martensitic structure with a high strength. Furthermore, a tempering occurs during the additive manufacturing process while welding several layers onto each other. This effect was investigated on martensitic steel AISI 420 [18], but can be assumed for tool steel as well. That is the basis for the adaptation of the heat treatment. After a conventional heat treatment with austenitization and three times tempering, the compression yield strength of both the additivelyand conventionally-manufactured material is at about $1645 \mathrm{MPa}( \pm 8 \mathrm{MPa})$. A substitution of the austenitization at the heat treatment of the additively-manufactured specimens results in a compression yield strength of about $1940 \mathrm{MPa}( \pm 13 \mathrm{MPa})$. This is even higher than conventionally-manufactured material after hardening without tempering. Regarding the standard deviation, the experiments demonstrate a high reproducibility for each heat treatment condition.

a)

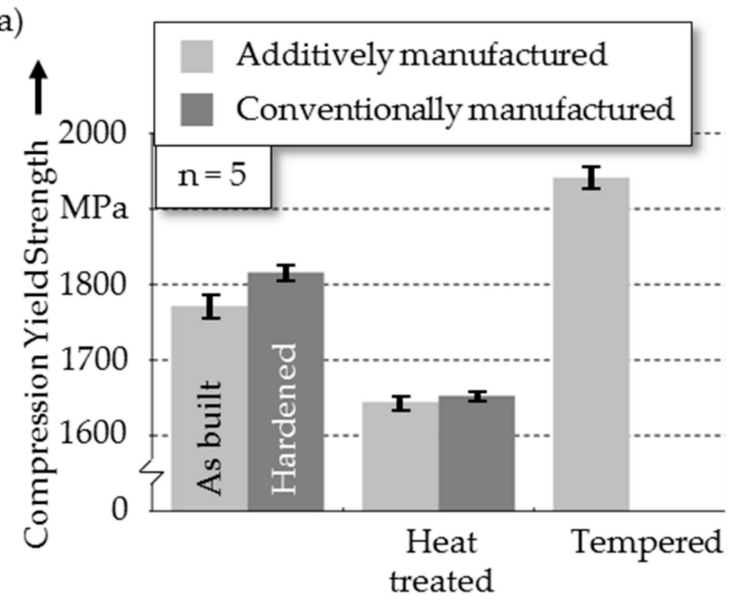

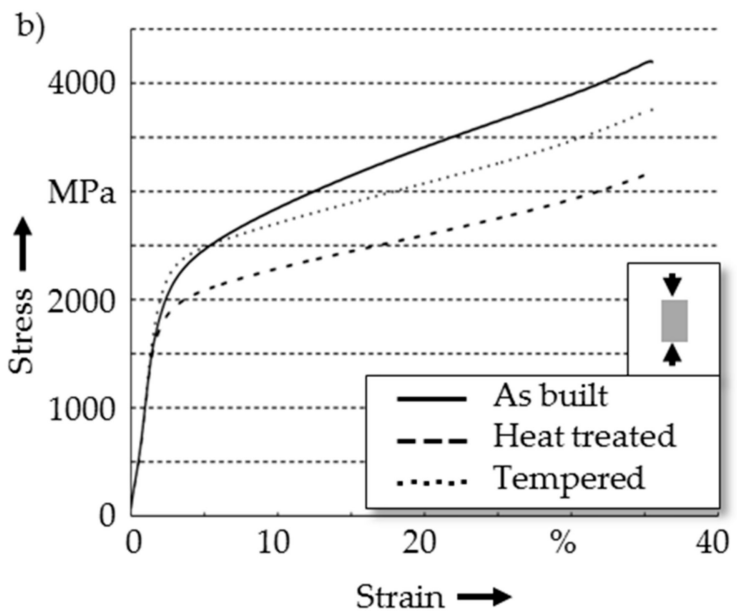

Figure 6. Results of compression tests with an analysis of (a) the compression yield strength and (b) the stress-strain curves exemplarily for one of the specimens with different heat treatment.

Analyzing the stress-strain curves presented in Figure $6 \mathrm{~b}$, all specimens could be formed to a compression of $35 \%$ of the initial height without fracture. Further on, the results indicate that the forming behavior of the tempered specimens is similar to that of the heat-treated ones, but is about $400 \mathrm{MPa}$ higher. Although the compression yield strength of the tempered specimens is higher, the strain hardening of the specimens directly after additive manufacturing has a steeper rise. Thus, at a strain of about $5 \%$, the stress-strain curve of the additively-manufactured specimens intersects that of the tempered ones.

\subsection{Tensile Tests}

In addition to the compression tests, tensile tests are conducted for the additively-manufactured specimens with different heat treatments. As a reference, conventionally-manufactured material is tested after conventional heat treatment. In Figure 7 the corresponding yield strength and ultimate tensile stress are presented. Without heat treatment, the additively-manufactured specimens have quite low yield strength, i.e., about $860 \mathrm{MPa}( \pm 8 \mathrm{MPa})$, but a strongly increasing strain hardening afterwards, until an ultimate tensile strength of about $1710 \mathrm{MPa}( \pm 170 \mathrm{MPa})$. At this point, the specimens break without necking with a plastic elongation at break of about $5 \%$, shown in Figure $7 \mathrm{~b}$. After conventional heat treatment, the yield strength could be increased to $1480 \mathrm{MPa}( \pm 1 \mathrm{MPa})$. This is similar to the yield strength of the conventional material with $1510 \mathrm{MPa}( \pm 12 \mathrm{MPa})$. The same applies to the ultimate tensile stress, whereas both materials reach about $1800 \mathrm{MPa}$. Similar to the results of the compression tests, the mechanical properties after conventional heat treatment of specimens manufactured by LMD are as good as those of conventional material. 
As seen in the results of the compression tests, the strength of the material can be increased by only tempering the additively-manufactured specimens. For this heat treatment, the yield strength reaches about $1630 \mathrm{MPa}( \pm 9 \mathrm{MPa})$, which is about $100 \mathrm{MPa}$ higher than after conventional heat treatment. The ultimate tensile strength is analyzed to $2130 \mathrm{MPa}( \pm 10 \mathrm{MPa})$, which is about $300 \mathrm{MPa}$ higher than conventional material. Regarding the elongation at break in the stress-strain curves in Figure $7 \mathrm{~b}$, it can be recognized that the ductility after tempering is slightly lower than after conventional heat treatment, but is increased in comparison to the "as built" condition.
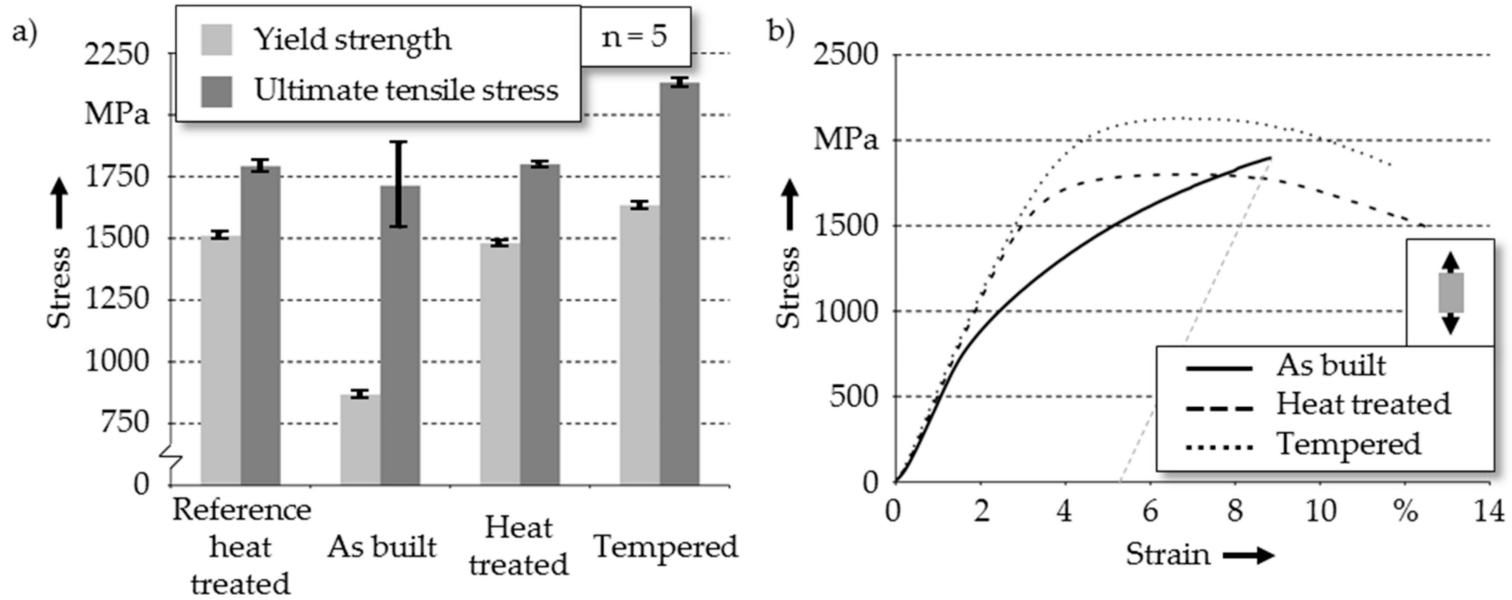

Figure 7. Results of tensile tests with an analysis of (a) the yield strength, and (b) the stress-strain curves which are exemplary of one of the specimens with different heat treatment.

\subsection{Metallographic Analysis}

To analyze the reason for the higher strength after tempering, the microstructure is investigated to identify structural variations due to the heat treatment. Thereby, cross sections of the additively-manufactured structures after different states of the heat treatment are polished, etched with V2A mordant, and analyzed with an optical microscope. The scale structure, depicted in Figure 8 (1a), results after additive manufacturing without heat treatment, caused by welding one track next to each other. This structure is due to the heat-affected zone of the single welding tracks. Using a higher magnification, shown in Figure $8(1 \mathrm{~b})$, a fine-grained structure is detected with a martensitic and dendritic structure inside the grains. At the grain boundaries, some retained austenite can be identified. After austenitization and quenching, the scale structure is dissolved, as depicted in Figure 8 (2), which leads to a homogenous martensitic structure with little retained austenite. During three times tempering, the retained austenite transforms to martensite as it is realized in conventional material, as illustrated in Figure 8 (3). Analyzing the microstructure after heat treatment without austenitization, which is shown in Figure 8 (4a), the scale structure is still identified. Due to the moderate temperature during tempering, the structural homogenization observed after hardening does not occur. Having a closer look at the microstructure, shown in Figure $8(4 \mathrm{~b})$, we see that the analyzed fine-grained structure that results after LMD still exist. The retained austenite that was between the grains transforms to martensite during tempering [19]. Also, the dendritic structure changed to a more homogeneous structure inside the single grains. Comparing the microstructures after a heat treatment, the main difference of a conventional heat treatment with austenitization and only tempering after additive manufacturing is the existence of grain boarders. After conventional heat treatment, the martensitic structure is similar to that of the conventional material. In general, a fine-grained structure, as it exists after additive manufacturing, results in a bad formability and a high strength of metallic material [19]. 


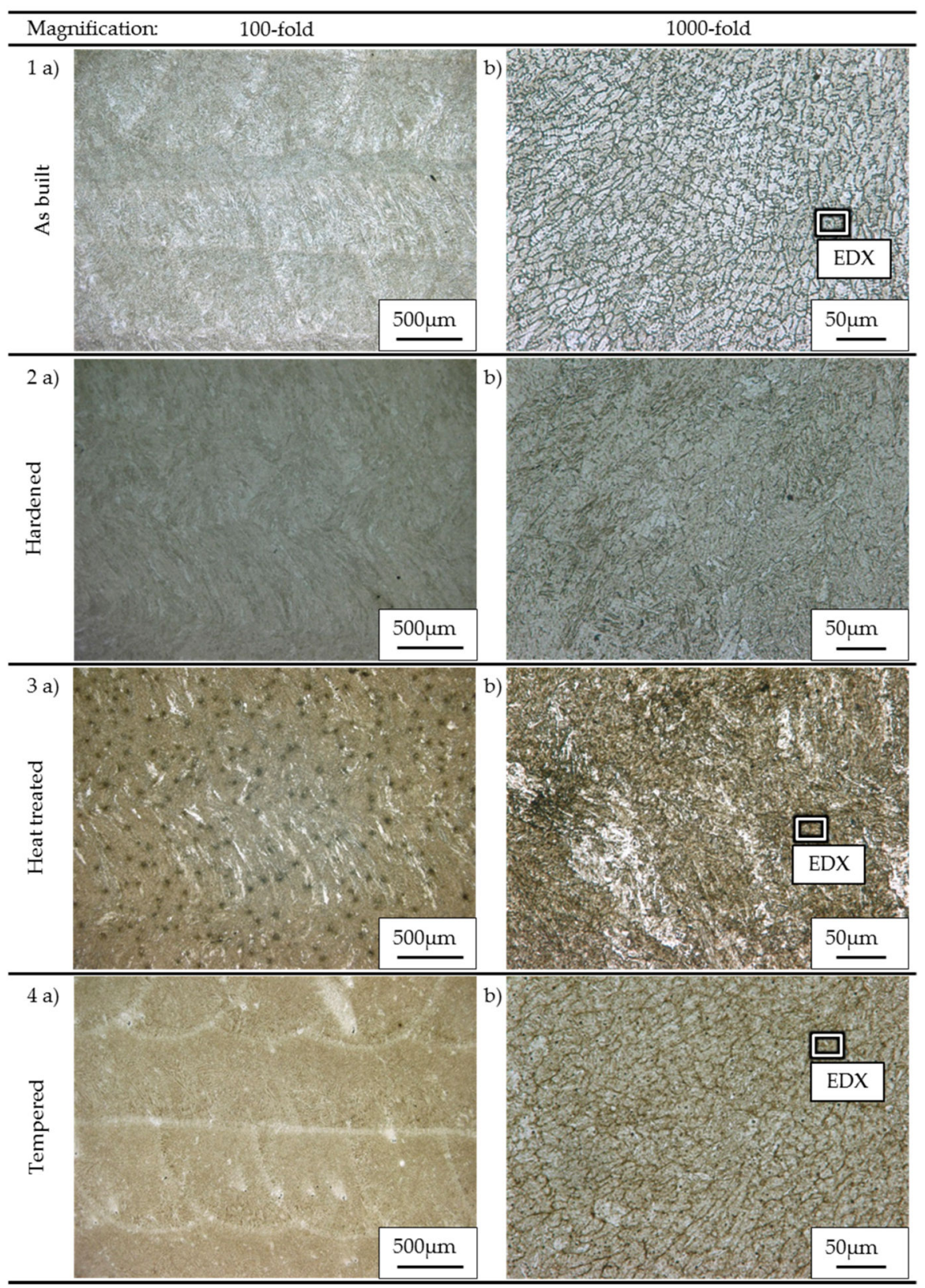

Figure 8. Microstructure of additively-manufactured hot work tool steel X37CrMoV5-1 after different heat treatments analyzed on cross sections etched with V2A-mordant for $15 \mathrm{~s}$. The microscopic analysis is depicted with (a) 100-fold and (b) 1000-fold magnification for the different heat treatment conditions of (1) no heat treatment (as built), (2) austenitization and quenching, (3) conventional heat treatment and (4) three times tempering without preaustenitization.

To investigate the distribution of the elements which have the main influence on hardness and mechanical properties, an analysis is conducted using energy-dispersive X-ray (EDX) mapping. The results of the carbide-forming elements of the tool steel X37CrMoV5-1 are illustrated in Figure 3. For the element distribution in the specimens without heat treatment, shown in Figure 9 (1), accumulations of chromium and molybdenum within the ferrite structure can be analyzed. Within these areas, the amount of carbides could be higher. During austenitization, these accumulations got dissolved, and a homogeneous distribution of the carbide-forming elements is realized, which is depicted in Figure 9 (2). 


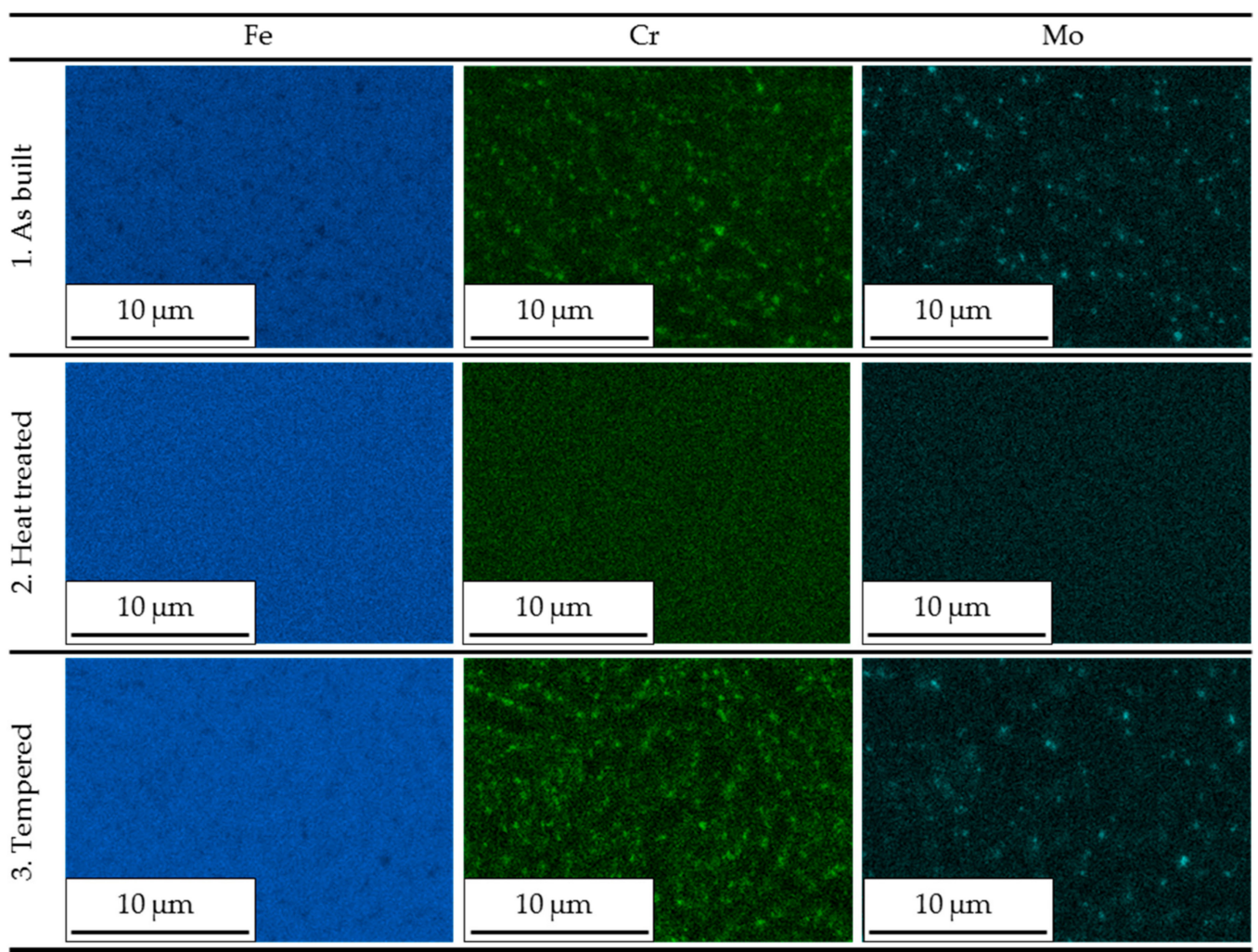

Figure 9. Energy-dispersive X-ray (EDX)-analysis of the distribution of the main alloying elements ferrite, chromium and molybdenum inside the microsructure of additively-manufactured hot work tool steel X37CrMoV5-1 after different heat treatments in (1) as bulit, (2) heat treated and (3) tempered condition.

The temperature during tempering cannot totally homogenize the microstructure by only tempering the additively-manufactured specimen; therefore, the accumulations of chromium and molybdenum are not dissolved in "tempered" conditions, as shown in Figure 9 (3). Comparing the results of the EDX mapping of the "as built" and the "tempered" conditions, it can be analyzed that the carbide accumulations grow during tempering due to the formation of carbide precipitations. Analyzing the specimens by an X-ray diffraction, a portion of retained austenite of about $33 \%$ can be measured for the specimen in "as built" conditions. After the conventional heat treatment, as well as after tempering without austenitization, no retained austenite can be detected.

\section{Discussion}

Analyzing the presented results in the context of tool manufacturing for bulk metal forming, the requirements on tool materials must be taken into consideration. To guarantee an increased tool life, high hardness, as well as high yield strength are necessary for wear reduction. Furthermore, high ductility prevents early fatigue of the tool. After additive manufacturing, a high hardness is measured, which is even higher than that of the conventionally-manufactured material after austenitization and quenching. This can be explained by the fine-grained martensitic and dendritic microstructure that results from the high cooling during the LBM process. Furthermore, the carbide accumulations could lead to increased hardness. This is also the reason for the relatively high compression strength, which is similar to the compression strength of conventionally-manufactured material after hardening. The ductility is investigated by analyzing the results of the tensile tests. After an early plastic deformation at a relatively low yield strength, the additively-manufactured specimen reaches an ultimate tensile strength which is comparable to that of conventionally-manufactured material, as it is commonly used in tool manufacturing. 
Determining the plastic elongation at the break from the stress-strain-curve, it is identified that the fracture occurs at the point of the ultimate tensile strength, what indicates a brittle behavior. The relatively high standard deviation of $\pm 170 \mathrm{MPa}$ of the ultimate tensile strength could result from the brittle fracture behavior and slight variations of the retained austenite which is analyzed within the metallographic analysis. A content of $33 \%$ of retained austenite forms a netlike structure between the fine grains throughout the whole material. Especially by considering the results of the tensile tests, it can be recognized that elements of the tool steel X37CrMoV5-1 have to be heat treated after additive manufacturing using LMD. As the hot work tool steel X37CrMoV5-1 is commonly used in tool manufacturing, a heat treatment strategy of austenitization, quenching, and three times tempering is established to receive ideal mechanical properties. Using this heat treatment strategy for additively-manufactured elements, the mechanical properties like hardness, and tensile and compressions strength, are similar to those of conventionally-manufactured specimens after the same heat treatment. During austenitization, the microstructure of the additively-manufactured element is dissolved and equals the microstructure of conventionally-manufactured material. Since additively-manufactured parts of the tool steel X37CrMoV5-1 have similar material properties to conventionally-used material, it could be used successfully for forging tools in serial production, as resented by the authors in [20]. Due to the high hardness and the high compression strength which are similar to conventional material after hardening, and the martensitic and dendritic microstructure, an adopted heat treatment of three times tempering without austenitization is conducted with the additively-manufactured elements. During the three times tempering, the retained austenite transformed to martensite, as shown by the XRD measurement. Analyzing the material properties, an increased hardness is identified compared to that resulting from conventional heat treatment. Additionally, an increased compression as well as tensile strength results from the adapted heat treatment. Comparing the ductility of conventionally-heat-treated and only tempered specimens by analyzing the plastic elongation at the break, a slight decrease of about $1 \%$ can be identified. As a plastic elongation at break of about $9 \%$ is realized after necking, the material still has a high ductility to resist alternating load. It can be concluded that the reduction of the ausenitization during the heat treatment of additively-manufactured hot work tool steel X37CrMoV5-1 promises high potential for increased tool life.

\section{Summary}

The presented work evaluates the potential of an adapted heat treatment for hot work tool steel after additive manufacturing by the Directed Energy Deposition process Laser Metal Deposition. It is proven that an in-situ hardening occurs during additive manufacturing due to the fast cooling from a molten to a solid state, resulting in a fine-grained martensitic and dendritic structure and high hardness. The compression strength is similar to that of conventionally-manufactured material after hardening, but within tensile tests, a low yield strength is observed. Using a conventional heat treatment with austenitization, quenching, and three times tempering, the mechanical properties of additively-manufactured material are similar to those of conventionally-manufactured material after the same heat treatment. Taking the creation of the martensitic structure during additive manufacturing into account for a post heat treatment, the process step of hardening is not necessary to produce this structure. By tempering the additively-manufactured material without preaustenitization, a fine-grained structure can be maintained. Using this heat treatment strategy, the mechanical properties could outperform those of conventionally-manufactured material, and have high potential to improve the life span of the tool. The influence of different process parameters on the LMD process, and their influence on the presented behavior during heat treatment, as well as different types of heat treatment strategies, must be analyzed in further investigations. 
Author Contributions: D.J. prepared the design of experiments, conducted the experiments for the material characterization and the metallographic analysis and wrote and edited the paper. O.H. conducted the experiments to process the tool steel by LMD and fabricated the semi-finished products for the specimens. M.S. and M.M. are heads of the involved institutes and supervised the project.

Funding: The work presented in the paper was founded by the Bavarian Research Foundation (BFS) in the course of the Research Association "ForNextGen-Next Generation Tools".

Conflicts of Interest: The authors declare no conflicts of interest.

\section{References}

1. Gebhardt, A. Generative Fertigungsverfahren: Additive Manufacturing und 3D Drucken für Prototyping-Tooling-Produktion, 4th ed.; Carl Hanser: München, Germany, 2013; ISBN 9783446436510.

2. ASTM International. Additive manufacturing-General Principles-Terminology; ISO/ASTM 52900:2018; ASTM International: West Conshohocken, PA, USA, 2018.

3. Frazier, W.E. Metal Additive Manufacturing: A Review. J. Mater. Eng. Perform. 2014, 23, $1917-1928$. [CrossRef]

4. Toyserkani, E.; Khajepour, A.; Corbin, S. Laser Cladding; CRC Press: Boca Raton, FL, USA, 2005.

5. Huskic, A.; Behrens, B.-A.; Giedenbacher, A.; Huskic, A. Standzeituntersuchungen generative hergestellter Schmiedewerkzeuge. Schmiede J. 2013, 92013, 66-70.

6. Kempen, K.; Yasa, E.; Thijs, L.; Kruth, J.-P.; Van Humbeeck, J. Microstructure and Mechanical Properties of Selective Laser Melted 18Ni-300 Steel. Phys. Procedia 2011, 12, 255-263. [CrossRef]

7. Weisheit, A.; Fuchs, E.; Bankowski, M.; Freyer, C. Multifunktionale Gradientenwerkstoffe für den Werkzeugbau; Fraunhofer Institut für Lasertechnik: Aachen, Germany, 2006.

8. Mazumder, J.; Dutta, D.; Kikuchi, N.; Ghosh, A. Closed-loop direct metal deposition: Art to part. Opt. Lasers Eng. 2000, 34, 397-414. [CrossRef]

9. Junker, D.; Hentschel, O.; Schmidt, M.; Merklein, M. Qualification of Laser Based Additive Production for Manufacturing of Forging Tools. In Proceedings of the 4th International Conference on New Forming Technology (ICNFT 2015), Glasgow, UK, 6-9 August 2015.

10. Wang, Y.; Tang, H.; Fang, Y.; Wang, H. Microstructure and Mechanical Properties of Hybrid Fabricated 1Cr12Ni2WMoVNb Steel by Laser Melting Deposition. Chin. J. Aeronaut. 2013, 26, 481-486. [CrossRef]

11. Balla, V.K.; Bose, S.; Bandyopadhyay, A. Processing of Bulk Alumina Ceramics using Laser Engineered Net Shaping. Int. J. Appl. Ceram. Technol. 2008, 5, 234-242. [CrossRef]

12. Freiße, H.; Khazan, P.; Stroth, M.; Köhler, H. Properties of large 3D parts made From Stellite 21 through direct powder deposition. In Proceedings of the Laser in Manufacturing Conference 2015, Bremen, Germany, 22-25 June 2015.

13. Telasang, G.; Majumdar, J.D. Effect of laser parameters on microstructure and hardness of laser clad and tempered AISI H13 tool steel. Surf. Coat. Technol. 2014, 258, 1108-1118. [CrossRef]

14. Hentschel, O.; Scheitler, C.; Fedorov, A.; Junker, D.; Gorunow, A.; Haimerl, A.; Merklein, M.; Schmidt, M. Experimental investigation of processing the high carbon cold-work tool steel 1.2358 by LMD for the additive manufacturing of cold forging tools. J. Laser Appl. 2017, 29, 022307. [CrossRef]

15. DIN 50106, Testing of Metallic Materials_Compression Test at Room Temperature; Deutsches Institut fur Normung E.V. (DIN): Berlin, Germany, 2016; DIN 50106:2016-11.

16. DIN EN ISO 6892-1, Metallic Materials-Tensile Testing-Part 1: Method of Test At room Temperature; Deutsches Institut fur Normung E.V. (DIN): Berlin, Germany, 2014; EN ISO 6892-1:2014.

17. DIN 50125, Testing of Metallic Materials-Tensile Test Pieces; Deutsches Institut fur Normung E.V. (DIN): Berlin, Germany, 2016; DIN 50125:2016-12.

18. Krakhmalev, P.; Yadroitsava, I.; Fredriksson, G.; Yadroitsev, I. In situ heat treatment in selective laser melting martensitic AISI 420 stainless steels. Mater. Des. 2015, 87, 380-385. [CrossRef] 
19. Berns, H.; Theisen, W. Eisenwerkstoffe-Stahl und Gusseisen, 4th ed.; Springer: Berlin, Germany, 2008.

20. Junker, D.; Hentschel, O.; Schramme, R.; Schmidt, M.; Merklein, M. Performance of Hot Forging Tools built by Laser Metal Deposition of Hot Work Tool Steel X37CrMoV5-1. In Proceedings of the Laser in Manufacturing Conference 2017, Munich, Germany, 26-29 June 2017. 